\title{
Humor as Monotony Breaker in Funny Ads: A Multi-Modal Discourse Analysis of Ads of Pakistani Ufone \& Jazz Cellular Companies
}

\author{
Fatima Zafar Baig ${ }^{1}$, Saima Umer ${ }^{2}$, Muhammad Zammad Aslam³ ${ }^{3}$, Muhammad Shehzad Razaq ${ }^{1}$, Samina Khan $^{1}$ \& \\ Tauseef Ahmad ${ }^{1}$ \\ ${ }^{1}$ National College of Business Administration \& Economics, Multan, Pakistan \\ ${ }^{2}$ National University of Modern Languages, Islamabad, Pakistan \\ ${ }^{3}$ National University of Modern Languages, Islamabad, Pakistan \\ Correspondence: Muhammad Zammad Aslam, National University of Modern Languages, Islamabad, Pakistan. \\ E-mail: zammad.aslam@gmail.com
}

Received: September 21, 2019 Accepted: November 1, 2019 Online Published: December 15, 2019

doi:10.5539/ijel.v10n1p69 URL: https://doi.org/10.5539/ijel.v10n1p69

\begin{abstract}
The present study explores and analyzes the role of humor in the advertisement as the message in advertisements keeps a pivotal value constructing and promoting the idea of promotional activity by any company. So, the companies and promoters of products utilize and employ various distinctive and discursive strategies to promote their products focusing on the interests of their consumers. The research concludes that Pakistan is the one amongst other countries, in which, advertisers and promotors utilize humor as an important feature in advertainments at a huge level. Along with entertainment, the promoters promote the text and its discourse through humor which influences the decision-buying process of consumers. However, they often try to utilize humor neutralizing the social or personal values. Recent studies prove that intelligent and sensible use of humor by the companies can lead them to success if it is more relevant to the products' nature and function. A Multi-Modal Approach, employing Fairclough's (1989) 3D model along with Kress and van Leeuwen's (1996) grammar of visual design, is employed to analyze data. The findings of the study suggest that the humor if handled properly, can play a vital role in captivating consumers' interest towards the product as it takes them away from the tensions of life and makes the product more appealing. Moreover, humor as a monotony breaker makes the ad more attractive that ultimately adds to the promotion of the product.
\end{abstract}

Keywords: humor, advertisements, multimodal, Fairclough's 3D model

\section{Introduction}

This research analyzes the importance of humor utilized by the advertisers and promotors of products of telecom companies in Pakistan i.e., Ufone and Jazz (Mobilink). For instance, telecom industry (in Pakistan) would merge humor in advertisements to attract customers as the life of Pakistani people is full of depression along with other chronic diseases (Godil et al., 2017). So, the trust level would be increased if the advertisements and promotions keep a significant level of humor to re/shape anti-depressive ideologies (WEFUSA, 2016, p. 13). Hence, the people of the society want to see the humor in any shape in their daily routine of busy life, for instance, the comedy shows on media channels keep record-breaking popularity in Pakistan as the humor included in these shows work as the best therapy (Abid \& Bilal, 2018, p. 46). It's the nature of humans that s/he only can see miseries and sufferings for a limited time and after this s/he would want to return a normal life, so that, humor is a natural way to make the disastrous life normal within a short time frame (Louie, Brook, \& Frates, 2016). Hence, the cellular network companies, specifically in Pakistan, utilize humor feature in advertisements to add more value to their products and services with reference to their consumption (Haider \& Shakib, 2017).

The integration of humor in advertisement discourse by the telecom companies is not for altruistic reasons rather, it is one of the discursive strategies, employed by the cellular companies to sell their products to make high profits (Chang \& Chang, 2014). In recent scenario, the number of telecom companies is increased to an extent, which add more competition in making the product more desirable than other products/services (ibid). Therefore, to make the product noticeable, the telecom companies now need to be highly vigilant and tactful in projecting 
their products properly to gain consumers' interest, as there are a huge number of products which are at ignorance level. So, the advertisement market become a huge business yet having a very high level of competition in it. For instance, Shimp (2010) argues that the companies introduce 25,000 new products every year and they promote their products through, approximately 6,000 advertisements daily. Therefore, they pay serious attention to promote and advertise their product (Koneska, Teofilovska, \& Dimitrieska, 2017). In the total market of advertisement, $30 \%$ of advertisers and promoters utilize the feature of humor to attract their consumers as an emotional appeal (Nwankwo et al., 2013, pp. 230-231). Henceforth, various companies still not utilize humor as they keep a serious nature of products. Some people wouldn't attract those types of advertisement which include humor (Hopkins, 1923 as cited in Koneska, Teofilovska, \& Dimitrieska, 2017). Various researchers and experts, specifically in the field of advertisement, suggest various ways to advertise products. For instance, Sekulovska (2007) suggests various guidelines to promote products specifically merging humor with them (as cited in Koneska, Teofilovska, \& Dimitrieska, 2017, p. 117).

\subsection{Significance}

This study aims at analyzing two cellular networks' funny advertisements in terms of the way humor is monotony breaker along with looking deeply into the interdiscursivity as employed incorporating humor as main facet in the discourse of the advertisement of the two famous mobile networks in Pakistan. Therefore, the study may be a significant addition in the existing body of the knowledge with reference to humor as 'monotony breaker' (Atta, 2011) as relatively very less work has been conducted regarding humor as an element in advertisements in Pakistani context. Moreover, the use of interdiscursivity to project humor as an embodiment of products' propagation along with the verbal sign and the nonverbal sign, that is, to identify the purpose, message and implication of power behind the funny advertisements in re/shaping an ideology add more to the value of the present study.

\subsection{Statement of the Problem}

Today, advertisements play an important role in communicating messages; it is an inherent part of our daily life. Among others, advertising contributes to the creation of opinions, the production of certain roles that viewers take up after their idols and the creation of shared knowledge. Advertisement is not only an economic entity, but it also deals with values, attitudes, and ideas shaping culture. Advertising is a social practice, that does not work in vacuum; it interlinks many things together like person and object, symbol, symbolism and power, and communication and satisfaction. To be truthful, we cannot separate the content of an advertisement from culture. It is in this context the study aims at exploring the role of humor in shaping and reshaping desired ideology (ies) in funny telecom ad/s of Ufone and Jazz (the two famous cellular networks in Pakistan). Moreover, the use of discursive strategies in highlighting humor as 'monotony breaker' (Atta, 2011) and as an embodiment of ideology proliferation is an important aspect to be explored with an analytical view.

\subsection{Research Questions}

1) How humor can shape or reshape desired ideology (ies) in telecom ad/s?

2) What are the discursive strategies used in the advertisements of Ufone and Jazz cellular networks to proliferate ideology through humor?

\section{Theoretical Framework}

The present study analyzes the significance of humor as monotony breaker in cellular companies' ads. For this purpose, the research accesses Kress and van Leeuwen's (1996) model for image analysis and Fairclough's (1989) DCA model which explains the analytical paradigm of CDA as multimodality integration. The present study analyzes two funny ads of two competing mobile network companies of Pakistan revealing the ideologies and intentions which would be represented through these ads. For this, Fairclough (1989, 1992, 1995a, 1995b) develops, a three-dimensional aspect model; description, interpretation, and explanation, as a model of CDA (specifically for media discourse), to analyze in detail the micro themes at description and interpretation levels and macro themes with reference to ideological formation at explanation level. For instance, Fairclough (1992) argues that people understand each other's actions through discourse as a responsibility (Aazam et al., 2019, p. 192). Therefore, Media discourse would be done employing multidimensional theoretical frameworks, in which, the social practice must be related to the discourse practice (Fairclough, 1989). So, social practice contains discourse practice as a form which takes part in the constitution of social relations and social identities in the social world (Bardici, 2012, p. 27). Therefore, social practices and discourse practices in social circumstances would be studied employing the above-mentioned tools (Baig et al., 2019, p. 254). On contrary, Kress and van Leeuwen (1996) argue that images keep their own grammar and rules, for instance, language and visual give a 
distinctive meaning in communication according to culture having independent forms of meaning (p. 17). Therefore, images and languages can be considered as two diverging systems, which form, shape, influence or even build the same culture. Therefore, to analyze a video made up of visuals and language both these two models are incorporated together as multi-modal messages. The two theoretical frameworks are discussed in detail in the section of methodology (See Methodology section for more details).

\subsection{Literature Review}

The importance of advertisement is steadily increased in modern society as it affects consumers' preferences (Scozzafava et al., 2019, p. 2). Advertisements play an essential role in imparting messages, providing useful information and benefits to the consumers about products or services, thus molding their views and opinions by creating an image of the product in the costumer's mind (Elbers, 2013, p. 8). It is also responsible for generating desires and certain roles that viewers take after watching their idols, and the creation of shared knowledge (Muda, et al., 2017, p. 22). According to Sinclair (1987), advertisement is not only an economic entity, but it also deals with values, attitudes, and ideas shaping culture. Just as the media of social communication it also carries enormous influence everywhere, so advertising, using media as its vehicle, is a pervasive, powerful force shaping attitudes and behavior in today's world. Advertising is a social practice which does not work in vacuum; it interlinks many things together like person and object, symbol, symbolism and power, and communication and satisfaction (Abdelaal \& Sase, 2014, p. 254). Honestly, the content of an advertisement from the culture cannot be separated (ibid).

\subsubsection{Semiotics in Advertisements}

In print advertisements, photographs are the main essence to construct a visual reality and give meaning to consciousness through signs and symbols. Visual and verbal modes of communication, the main ingredients used in print media, when interacts together through different utilized signs such as color photographs or type words, give meaning to an advertisement. The more efficiently they are used, the more efficiently a customer is persuaded to buy products. It can be said that discourse and ideology are interlinked to one another through semiotics references (Najafian \& Dabaghi, 1991).

\subsubsection{Critical Discourse Analysis (CDA) in Advertisements}

Fairclough (1989) characterizes CDA as a sort of social practice where power and ideology impact and cooperate with each other. Dijk (1995) likewise characterizes critical discourse analysis as a sort of exposition of social power misuse, strength and disparity, and how they are reproduced, enacted and resisted. Advertisements have molded and swayed the ideology of beauty. Beauty products advertisements, mainly cosmetics, persuade and convince the customers in a way that they are compelled to believe that whatever they are saying is true (Kaur et al., 2013).

\subsubsection{Humor in Advertisements}

Humor is another tool for advertisements to sell products and no wonder people are appealed through this idea. People nowadays simply shop for fun, pleasure, and enjoyment. And then advertisements using humor for their sale are considered as a cherry on top of the cake. If taken a glance back, many of the famous advertisement campaigns are memorable because they were funny and intriguing. A dictionary definition of humor is the quality of being amusing or comic, the ability to express humor or amuse other people, a mood or state of mind (Oxford Dictionary). Still, humor is not confined to this definition rather is perceived in a vast way. Weinberger and Gulas (1992) also state in their work that a general definition of humor does not exist. Humor is the word that people are familiar with all around the globe and still yet is the hardest to define (Weinberger \& Gulas, 1992).

Despite being used abundantly, humor remains controversial in advertisements. From one viewpoint, humor has been attributed withdrawing into consideration regarding a promotion, expanding perception of the advertisement, adding to the inspirational demeanor toward the ad and enhancing the positive attitude towards the advertisement. While on the other hand, humor is not always the best choice in certain cases, it may offend the customers creating a "wear-out" effect or resulting in the so-called "vampire-effect" which drains the humor out of the advertised products or messages. According to Kotler (2004), humorous advertisements can be differentiated and characterized according to the nature that what kind of humor would be suitable for certain advertisements; puns, satire, jokes, slapstick, irony, and incongruities (as cited in Mehmood \& Masood, 2016). Catanescu and Tom (2001) provide a detailed categorization i.e., a) comparison, b) personification, c) exaggeration, d) pun, e) sarcasm, f) silliness, g) surprise, f) blue humor, g) black humor (see Koneska, Teofilovska, \& Dimitrieska, 2017, pp. 117-118, for details). The study of Catanescu and Tom's (2001) 
demonstrates that humor is widely used in television as compared to print advertisements. Their studies show that television is a progressively effective medium to use humor whereas magazines are highly imbued to sarcasm i.e., a form of humor. While goofiness and silliness are much appreciated in televisions. Humor provides mental relaxation to the audience, tends to break the ice and builds a bridge between the communicator and the audience (Tellis, 1998 as cited in Koneska, Teofilovska, \& Dimitrieska, 2017).

\section{Research Methodology}

The present research is qualitative in nature employing Fairclough's 3D model along with Kress and van Leeuwen Grammar of Visual Design (1996). In order to find out the effectiveness of humor as a persuasive technique and monotony breaker (Atta, 2011) in consumer's purchase behavior, two funny advertisements of Ufone and Jazz from YouTube are downloaded and analyzed. The publishing date of the Ufone ad on YouTube is 26 July 2010 and the Jazz publishing date is 10 Oct 2010. Both ads are funny and selected from the same timeline. The multimodality inclusive of Fairclough's 3D model (1989) and Kress and van Leeuwen's Grammar of Visual designs (1996) is elaborated with reference to highlight the models and their analytical categories are as follows:

\subsection{Fairclough's 3D Model}

The present analysis is done in the light of Fairclough's model for critical discourse analysis working at three levels; description, interpretation, and explanation. CDA plays an integral role in uncovering the hidden implicit messages embedded in beautiful images and decorated musical settings. Every discourse is linked with the power relations and ideologies, so Critical Discourse Analysis aims to expose those ideologies and power relations. Chiapello and Fairclough (2002) find relations between CDA and social life, identities, institutions, and ideologies (p. 195). Through power structures, one (powerful) party becomes oppressor and controls the other one, the oppressed (Dijk, 1993, p. 254). These power structures are interlinked with ideologies in society. Fairclough (2003) further defines three dimensions for every discursive event: 1) a spoken or written text, 2) a discursive practice, that includes production and interpretation of a text, and 3) a piece of social practice incorporates the notion of macro theme based on ideological underpinnings as projected in the ads. Keeping in view the mentioned analytical categories of Fairclough's model, the model serves as an appropriate tool in doing this analysis because it reaches beyond the actual text perceived by the customer employing following three levels; description, interpretation, and explanation also known as the "text", "discursive practices" and "social practices".

\subsection{Kress and van Leeuwen's Grammar of Visual Design (1996)}

According to Kress and van Leeuwen (1996), Visual Designs contains a deep-rooted knowledge, known as Grammar of Visual Design, just as that of a linguistic structure. This grammar is perceived through a critical examining of cues and signs, that when constituted together, creates a meaning of their own. The grammar is history and culture-specific. According to Kress and van Leeuwen (1996), meaning is conveyed through design, production, and interpretation i.e., through using different modes and channels. They demonstrate two different components for visual discourse; Represented participants and Interactive participants. Represented participants are referred to as the people who are portrayed in the advertisements whereas Interactive participants indicate customers and buyers. Among these participants, there exist several relationships. The relation between represented participants is termed as syntactic, the relation between represented and interactive participants in demonstrated as semantic, whereas the relation between interactive participants is called pragmatic. Interactive participants are the real game-changer, the ones who interpret and make meaning out of a visual in reference to the social institutions i.e., keeping in view what ought to be interpreted and said in context to different degrees and ways. Hence it can be said, that there are four inseparable relations in an advertising discourse and are interlinked to one another to emit their functions. The first relation is between the images or between the represented participants, the next two are related to the positions of the producer and the receiver towards the image and the last one is related to these processes in a social sphere. In print advertisement communication, images play an important role in constituting a relationship between a producer and a receiver.

Another important aspect of mass media communication, apart from direct communication, is that of a producer and a receiver. There is a disjunction between the context of the producer and the context of the receiver due to the physical absence of the producer. Therefore, at times the information is not interpreted in a way in which it is acquired. Kress and van Leeuwen (1996) argue that the producers only create an image that they create according to their imaginary thoughts into any image or (video), hence, they don't know their audience's real mind about that picture or (video). Therefore, Barthes (n.d.) argues that the results and interpretations can only be intended after its release, for instance, every viewer keeps his/her own interpretation which would be against 
the producer's intention (Robinson, 2011). But still the interpretation and perception of a receiver is not limited to certain angles or codes, they have their own knowledge of the world, beliefs, attitudes, and expectations towards the received images and so thus intervenes the messages in different contexts and situations. In a word, it can be said that the integration of Visual Design Model by Kress et al. (1996) assist in validating the findings resulted from CDA application because words and images work in conjunction to create a powerful message/ideology.

\subsection{Procedure}

Since the analysis is based on Fairclough's 3D model and Kress and van Leeuwen's grammar of visual design, the procedure for each advertisement was as follow: at first each advertisement is analyzed based on the textual level followed by a semiotic analysis than the remaining two dimensions of Fairclough's 3D model, i.e., interpretation, and explanation are operationalized to analyze the ads one-by-one. However, as mentioned earlier that identifying the position of the producer is not an easy task, therefore, finding the position of the producers of these advertisements cannot be done, only the position of the receiver is defined for each advertisement (Robinson, 2011).

\section{Analysis of Advertisements}

The analysis of the funny advertisements of Jazz and Ufone cellular networks taken from YouTube is done one-by-one, employing analytical categories of both the modal and the analysis is as follows:

\subsection{Analysis of Jazz Funny Ad}

\subsubsection{Textual Level}

The first advertisement under analysis is of Mobilink/Jazz, which is of 1 minute and 30 seconds. The ad opens with the Mobilink/Jazz red monogram that leads into the outdoor setting of university cafeteria where camera moves from showing students moving, playing, eating and gossiping and goes close to two young students one in red check shirt and other in yellow shirt laughing loudly on a joke or talk cracked between them.

The ad can be divided into 5 scenes according to the occurrence of the events. In the first scene, the two guys in red and yellow shirts have shown as close friends as depicted by their sitting posture and talking style. While they are enjoying laughing over a joke, a waiter appears in with a note pad and pen in his hand wearing white shalwar kameez (cultural dress of Pakistan) with a check yellow and black safah (staller; a piece of cloth) on his left shoulder to take order. The two friends when looks at him say 'tu yahan bhi aa gya!' (trans. you also came here!) the waiter instantly says 'haan!' (trans. Yes!) but when he looks at them, he gets shocked and runs away.

The second scene starts with a dramatic entry of a young and slim girl in a red modern traditional outfit (with short sleeves and without dupatta) moving her left hand in her long open hair flying in the air with a bag on her right shoulder and a watch on her left wrist. On the other hand, the two friends are taken aback with mouth wide open (a musical sound of surprise in the background), the boy in yellow shirt place his hand on the eyes of the boy in red shirt so that he cannot see the girl. The girl seems coming towards the café and stops with a notebook in her hand at the table where two friends are sitting and asks excuse me: library? In the very scene, a talk starts among three characters (the friend and the girl) whereas a conversational fight between the two friends in order to get the girl's attention.

The third scene starts when the argumentation between two male friends comes to the point where the yellow shirt says, 'mei din raat subh sham 24 ghntay tum se batain kron ga' (trans. I will talk to you 24 hours, day and night!). This statement puts all of them (the girl, the red shirt and the waiter) in shock, which is depicted through their facial expressions, body movements, and falling of the tray from the waiter's hand).

The fourth scene is focusing upon introducing the 'Jazz na qablay yaqeen offer' (trans. Jazz's unbelievable offer!) by a male voice over informing and giving details about the offer and its activation process. The scene is accompanied by written text in the shape of captions on screen and the nonstop talking of the girl and young students (boys and girls) on phone in background. The scene ends on Mobilink/Jazz monolog with white backdrop depicting "reshaping lives" in black on the right side of the monogram and Jazz in red at the center bottom of the monogram along with 'Indigo' and 'infinity' on both sides in blue.

The last scene captures the waiter's monologue when he is sitting on stairs and saying 'sochta hon kon hoga jo is na qablay yaqeen offer se faida nhi uthaye ga!' (trans. I would think, who would not get benefited from this unbelievable offer!) while he says this the two friends in red and yellow shirt come close to him from both sides of the stairs and the boy in red says, 'sochtey kiun ho, tum hi tu ho' (trans. why would you think, it's you!) whereas, the boy in yellow is signaling via his hand towards him (the waiter) to accompany his friend's words 
'tum hi tu ho!' (It's you!).

As far as the details of the characters are concerned, the young drama celebrities famous for comic acts i.e. Mani, Sadia Khan et cetera are playing the roles of university students except for the waiter who is not a known person and a middle aged clean shaved man. Moreover, the students in the background are unknown as well. The male students are clean shaved and shown in westernized dressing wearing casual jeans, shirts, and girls in modern shalwar kameez (cultural dress). The lead-in red outfit is wearing natural makeover and is slim and tall.

The language of the ad is simple and mainly in Urdu. English is used very less in shape of codemixing lexical items like: right, no, assignments, attendance, lunch, friends and family, numbers, call, free, Jazz one, dial, and the complete monogram are in English. Moreover, the use of numerated expressions like *108\#, 03056785678, 24 ghantay (hours), bilkul muft (totally free), 6 rupee 99 paise and 3 friends are some of the examples.

As the ad is a video, therefore, it is a mixture of multiple discursive techniques like sound effects, colors, acting, voice-over, written captions and visual effects et cetera.

The intertextuality has also taken place with reference to the use of Ufone brand motto 'tum hi tu ho' and by using the waiter as a Ufone user along with the incorporation of the discourses from fashion, showbiz and music industries.

\subsubsection{Semiotic Analysis}

The recipients/characters of the ad are positioned at a high angle because the university café particularly the table and chairs, on which the two friends are sitting, seem to lie beneath them and are meant just to create the environment. Therefore, the power balance is on the side of the recipient and the use of long shot between the waiter and the two friends depicts a social distance, like all-day situation of our society, whereas the close shots between the two boys and the girl show intimacy and less social distance. Though the ad is a mixture of so many colors, but the main colors used in the ad are red, yellow, black, white and brown. These colors are used intentionally to create the ad eye-catching. The use of red color is in solidarity with product color. Moreover, objects like bags, note pads, books, chairs, tables, plates, and glasses are used to depict the setting of a university café.

\subsubsection{Interpretation Level/Discursive Practice}

This level of Fairclough's model aims at illuminating the discursive practices behind the ad by making a distinction between the production of the ad and its reception respectively to highlight its significance. In order to do so, the ad must be analyzed from the perspective of the viewers and producer as well, therefore, the ad needs to be further structured into the elements such as valuing, representing, relating and identifying. As the video is an ad projecting Jazz 24 ghantay (hours) package in a funny way, therefore, its duration falls in the discursive practice of cellular networks' funny ads. The ad is visualized at campus café comprised of young university students, depicts the lifestyles of university students whose more focus is on gossiping, eating and enjoying than on studies. Mainly, the guys in the very lead playing the main lead are shown as flirts when they see a young slim girl at the university café. Both try to capture her attention by offering her different services like, 'mein roz lunch krwaon ga, mein apne hathon se bna k laon ga, mein tmhari attendance lagaon ga (trans. I will have a lunch daily, I will make it with my own hands, I will mark your class attendance) et cetera'. Moreover, the use of red color in abundance like girls' red outfits, boys red tea shirts is in solidarity with the brand to make people remember the product color, so whenever, they see red they associate it with Jazz. Furthermore, as the ad has used the element of intertextuality by referring to Ufone's (competitor company) previous ad by saying the waiter 'tu yahan bhi a gya' (trans. you also came here!) who listening these words from these guys who know him as Ufone representative (consumer) gets perplexed and runs away. In the end, the taunt is done again by saying the words 'tum hi tu ho!' (trans. it's you!) in response to the waiter's monologue. The ad, overall, is a simple visualization of university students highlighting their activity of using the phone to talk to their friends (mainly females in case of boys and vice versa). In this context of university going students' mobile phone usage, offering a 24 hours free package for 3 friends and family numbers on very economical rates is like an icing on the cake for youngsters of the same age. The ad though is meant for the projection of their product package but also representing a lifestyle in line with postmodern trends of excessive use of mobile by the young generation not for the studies but for late-night (love/friendship) talks with fe/male friends and vice versa. The usage of Urdu as the main language is to make them more relevant and comprehensible for the general audience of Pakistan. Though the actual audience in the ad is the young generation but the use of interdiscursivity and waiter is reflecting that the intended audience is also there. As the funny advertisement also has an impact of a satire on their competing network Ufone in shape of waiter character as representative of the competing brand. The representative of other network is deliberately shown as 
the waiter to degrade the network and project it as substandard and of low class. Moreover, the ad depicts a clash between two very good university fellows just because of the young pretty girl who both like the moment they have seen her. Moreover, when the conflict between the two friends is in continuation, the girl gets attracted to the boy in yellow shirt (Mani) who allures her with her offer of rat din (day and night) 24 ghantay (hours) bat offer that is the time where product's projection gets started with its real essence.

\subsubsection{Explanation/Social Level}

In order for a discourse to make sense it must be understood in relation to its social milieu and according to Yates (2001), the importance of social contexts in the meaning-making of discourses by asserting that language use is embedded in a "context of situation" and that utterances only become understandable within this "context of situation".

The very ad under analysis is in collaboration with postmodern technologized era where the use of smartphones, exclusively by the young generation, has become an integral part of their livings today. The use of humor to make the ad more captivating is a new strategy to appeal to the viewer to make them buy the product. The ad represents the young slim tall female with fair complexion in an outfit with is traditional with modern touch. In this way, the very ad constructs a young female identity, with reference to the acceptable concept of femininity in the minds of Pakistani people and it voices the stereotypical notions with a modernized touch in terms of her dressing and hairdo. Moreover, the conflict between the two friends due to the girl's appearance in the ad in terms of getting her attention also highlights the stereotypical view about females being destructor of harmony and peace between males, here a reference can be made to 'Helen of Troy'. Additionally, it also represents males' weakness of falling for beauty at once.

\subsection{Analysis of Ufone Funny Ad}

\subsubsection{Textual Level Description}

The video under analysis presents a funny commercial of the Ufone mobile network comprised of 1 minute and 27 seconds. The ad is picturized in an outdoor setting of a road with cafes alongside. The ad can be divided into 6 scenes as per their order of events occurring. The first scenes open with a morning scene at the road where a young modern girl in westernized dressing (off white top and grey jeans) is shown walking towards a coffee shop across the road. The backdrop is in the shape of a brown large building comprised of many floors and white sky. The scene is boosted up with light guitar beat converting into a soft romantic song 'subha barish ki pehli bond jaisi teri awaz ka jado, hoa mei dewana pul bhar mei teri awaz ka jado' (trans. The sound of your voice is like the first drop of rain in the morning, the magic of your voice throughout the madness in the air) performed live by a street band outside the café playing guitar and drums. While the girl is walking to the café talking on her mobile a guy (wearing a black suit, black sunglasses sitting, on the front seat of a roofless black Mercedes) talking on his phone looks at the girl and immediately leaves the car. In the second scene, he (Mikal) goes after the girl who is now sitting on a café chair outside, the guy in black manages to sit on a table right in front of the girl's table and stares at the girl (who is still enjoying her talk on phone) from behind a menu card in his hands.

The third scene takes place when the girl leaves the table but forgets her cell phone on it which is noticed by Mikal and he quickly goes to the girl's table, picks the mobile up meanwhile the girl returns to get her mobile which is given to her by Mikal who says 'aaa! Aap ka mobile!' (your ... your cell phone!). The background is marked with the name of the cafes; Pizza Choice and Peets Coffee and Tea. The girl replies 'teri mehrbani' (thank you!) in an ugly, unclear, boyish voice. The guy in black modern suiting gets put upon hearing such an ugly voice and says 'haaainn?' (trans. whattt?) in shock and the girl reiterates 'mehrbani' (thanks!). The guy in black immediately turns his back towards the girl and starts walking away with funny facial and body expressions depicting shock.

While the guy is going away from the girl on hearing the ugly voice, the fourth scene starts where the package introduction of saaf awaz (trans. clear voice!) is done by a male voice over at the background of the scene. The male voiceover says, 'kuch bhi kaho, saaf awaz se frq parta tu hy, tu sirf Ufone daita hy apko saaf awaz, fori rabta, and wasee network, tu apko aur kia chahiye?' (trans. Say anything, clear voice does matter, then only Ufone gives you clean voice, instant connection, and wide network, so what else do you need?). The moment package introduction is over, the girl in her ugly unclear voice, inquires loudly in shock (on guy's going away from her), kia hoa? (trans. What happened?). Listening to the ugly voice of the beautiful girl the band sitting on the left of the girl gets frightened and runs immediately taking their instruments along.

The fifth scene starts with a Ufone monogram with lexical expressions 'Ufone, tum hi tu ho' (trans. Ufone, it's you!) in orange, green and black colors along with an orange backdrop. The words are written in large bold font 
incorporating Urdu and English languages. The product's monogram leads to a scene where the same girl is standing with a long hair strange funny looking guy in an orange robe with a beard and mustache. The girl is indulged in using her mobile phone and paying no heed to the guy in orange robe, who is trying to catch her attention saying 'aap bht khubsurat hyn!' (trans. You are so beautiful!). When the strange-looking guy does not get any response from the pretty girl, he says 'lagta hai merey signal saaf nhi pohnch rhey, Ufone lena parey ga!' (trans. I think, my network signals are not reaching clearly, I must buy Ufone!), with these words he leaves as if he is going to buy Ufone immediately.

Like the fifth scene, the sixth scene starts with the Ufone monogram with orange backdrop and written caption of 'Ufone, tum hi tu ho!' (trans. Ufone, it's you!) in Urdu and English both. This leads to a scene where two characters; the guy in black modern suiting and the strange funny looking guy in orange robe are standing before the black roofless Mercedes (owned by the guy in black suiting). The guy in black suiting is moving his car's key ring in his finger when the long hair guy in orange robe says to him, 'mujhe bhi chabi do, mujhe bhi line marni hy' (trans. Give me keys, I would like to flirt/draw a line!), Mikal who is still casually moving the keyring in his finger, gives the key to the guy in orange robe and asks, 'kis per?' (trans. On whom?). The guy in orange robe replies, 'teri gari key bonut pe! (trans. on your car!) (while saying this he makes a scratch on Mikal's car and runs away with a loud laugh). Mikal, the guy in black screams loudly with his mouth and eyes wide open on seeing scratch on his Mercedes and says, 'meri mout, Ammi ki report!' (trans. I am dead, I must report my mother!) while saying this he starts crying and gets down on the road with his car with depressed expressions and body movements.

The seventh and the last scene of the ad again starts with the same Ufone monogram displayed at the start of the fifth and sixth scenes respectively. The monogram this time enters a scene where the strange looking guy in orange robe is drinking coconut juice and the pretty girl asking him, 'log saaf awaz key piche kiun jate hyn?' (trans. Why do people go after clear voice?) In her ugly unclear voice. The guy in orange robe answers, 'pata nhi...' (trans. I don't know...) and with this, the pretty girl with ugly voice leaves that marks the ending of the ad.

Talking about the characters of the ad, many famous drama and comedy celebrities of Pakistani showbiz industry are playing the roles. Mikal (playing the role of main lead, the guy in black modern suiting), Jawad Bashir as the main vocalist of the band, Faisal Qureshi as the funny looking guy in orange robe. However, a foreigner Brazilian model named Carol Koerich performs the role of a modern pretty girl. Many unnamed unknown characters are also used in the background to represent the scene in a natural way as it happens normally at café and on the road. All the characters are males except for the Brazilian model.

The language of the ad is very simple with simple sentences. The whole ad is in Urdu mainly with a very light touch of English at the level of monogram captions written in Urdu and English both.

As the ad is a video, therefore, is inclusive of interdiscursive strategies in the shape of colors, visual and sound effects, acting, music, singing, and voice over. The discourses of the fashion industry, showbiz industry, the music industry, are integrated to make the ad entertaining and captivating.

\subsubsection{Semiotic Analysis}

The characters of the ad are positioned at a high angle as the outdoor setting of a café across the road is meant to provide the platform to perform the ad otherwise the focus is on the characters. The use of different camera angles horizontal and vertical with close, medium and long shots are meant to create a kind of intimacy and distance as per the requirements of different scenes. For instance, the camera angle during the scene between the pretty modern girl and the funny looking guy depicts a kind of a social distance. Though the ad is abundant in many colors but the colors like orange, green, off white, grey, brown and black are predominated. However, the orange color is the trademark of Ufone, therefore, its use in ad is in collaboration with the product color. All the male characters performing the act are clean-shaven.

\subsubsection{Interpretation Level/Discursive Practice}

This level of Fairclough's model aims at illuminating the discursive practices behind the ad by making a distinction between the production of the ad and its reception respectively to highlight its significance. Therefore, at the very outset of the analysis at this level, the interpretation of the ad's production will take place. The ad is a projection of Ufone 'saaf awaz' (trans. clear voice) package that marks a duration of 1 minute and 27 seconds that is in accordance with mobile network funny ads discursive practices. The ad's integration of different discourses (media, music, showbiz, visuals, symbols, and colors) is highly significant from the view of making it more appealing and captivating for the viewers to change their perception positively in favor of the product and 
to urge them to buy it. The ad depicts a romantic setting with a soft song in the background and revolves around the theme of first sight love. Though, the ad is comprised of Pakistani actors mainly and shows cars with right hand driving seats but the overall setting, the cafes' name, the street band performing at cafe and particularly the foreigner female model (Carol, the lead with Mikal) represents a foreign environment outside Pakistani context which is not that familiar to the viewers. Moreover, all this setting with expensive cars and westernized modern dressing of the girl and the guy along with the band's projection and dressing displays an elite lifestyle. However, the use of a comic character (Faisal Qureshi) with long hair wearing an orange robe gives a touch of familiarity to the viewers. As the ad employs humor to project the product, therefore, the use of comic elements like verbal expressions, the acting particularly the nonverbal, the sound effects and the camera angles are used very skillfully to convey and utilize humor in the best possible way.

\subsubsection{Explanation/Social Level}

The third and last level of the model deals with the so-called social practices, which refer to both macro-themes in the social world and our everyday perception of the environment we live in. The Ufone funny ad under analysis depicts a posh lifestyle, which can only be available to the rich. The use of an expensive roofless Mercedes with Mikal (an icon of male beauty in Pakistan) with a foreign Brazilian model Carol as his co-lead displays an ideology of beauty and lifestyle, which people ascribe. Though the main aim is to propagate the product but the way it is being related to the image of a beautiful girl is remarkable. The ad shows that a beautiful girl must have a clear beautiful voice along with a slim tall figure and white complexion. If the girl does not fulfill the required patriarchal Pakistani ideology of being beautiful in terms of voice and appearance, then she would not be liked by the males. The image of a girl has used her to satisfy the 'male gaze' as the foreigner model's outlook in terms of her attire and makeover is quite appealing that's why Mikal gets attracted towards her and leaves everything behind and rush towards her. Moreover, another theme depicted in the ad is about the female's mentality of falling for rich good looking clean-shaved well-dressed guys (Mikal) not for the ordinary-looking guy with beard and mustache (the guy in orange robe).

\section{Findings}

The following are the findings of the study:

The utilization of humor as a monotony breaker in advertisements especially of cellular networks is a significant tool, that takes the viewers away from their boring, depressed and hectic life routines to a lighter world of entertainment with fun. Through such humorous ads, the desired ideology can be propagated in a very subtle way. For instance, the patriarchal ideology promoted in both ads of Ufone and Jazz about the physique of young modern women as slim, tall with fair complexion and long open hair implies as if they do not possess mind but body that must be cared of. There is an idealization of thinness as a standard of feminine beauty and advertisers make use of young, thin, symmetrical, and perfectly shaped girls/women to sell a variety of products. Therefore, the construction of beauty ideal as slim and smart is a traditional stereotypical presentation of women in these ads. The ad appeals to the women with beauty idol, it instigates them to be slim and smart in order to get the attention of young university or rich guys. Since, both the ads are video-based, so they make use of visuals and sound effects to convey their messages effectively. Through the careful, choice of visuals and semiotic the ads successfully associate their products with the young generation exclusively and adult generation inclusively. Furthermore, the Ufone being the initiator of using humor in their ads for projection of packages stands out in terms of their direction and dramatization incorporating humor. The following are some similarities and differences which are found during the analysis of both the ads:

\subsection{Similarities Between the Both Funny Ads of Different Cellular Networks}

Though, both the mobile networks are rivals but have so many things in common in terms of making a funny ad to sell their products:

Both the ads of Ufone and Jazz have employed humor to sell their products by capturing the audience's attention through light entertainment in a funny way. They use different colors, but for the same purpose. Both are meant mainly for the young generation. Outdoor settings are distinctive in nature i.e. one in university café and one in a café on the roadside. Both include famous showbiz drama celebrities and picturized on young modern generation. Elements of modern music with singing are also included in both ads. Both are started with a male voice over to introduce the package and detail. Both ads include interdiscursivity at the level of music, symbols, sound effects, acting, colors, and written captions and mainly represented in the Urdu language with very little use of English. Both the ads have a greater number of male characters with a single female in the main lead.

Hence, the Ufone ad has a greater number of celebrities and seems funnier and well direct than the Jazz ad. It 
also seems that the Ufone ad is picturized in an unknown foreign setting whereas the Jazz ad is in accordance with a university setting in Pakistan. Moreover, the Ufone ad is presenting a lifestyle of elite class, on the contrary, the Jazz ad is depicting a casual lifestyle of today's modern university going students.

In conclusion, the Jazz ad has utilized satire technique to highlight their product and its features. They have made satire on Ufone. Whereas the Ufone ad is simply advertising the 'saaf awaz' (trans. clear voice) feature of their network.

\subsection{Implications}

This present research analyzes only two humorous advertisements specifically in the telecom sector. The framework of the present would be employed on the other companies' advertisements, and the results would be gained similar or distinctive. The sample size of the study would be enhanced selecting more than two advertisements. Moreover, a comparative study would also be done amongst the distinctive type of advertisements.

\subsection{Limitations}

The present research focuses only on a specific area in the vast field of advertisement industry in Pakistan. There were some social and cultural limitations. In the present advertisements, various taboo issues could also be analyzed yet couldn't due to cultural and social obligations. So, the researchers only focus on the general humor consciously.

\section{Conclusion}

It can be said that the ads though projecting their products apparently but are propagating an ideology (patriarchal) with a transitional aspect of modernized dressing and lifestyles. The ads depict that using these products make you associated with a lifestyle, which one ascribes to achieve. Moreover, the use of semiotic discourses and linguistic discourses together is a powerful means of constructing desired ideology as it is said that words and images work in collaboration to create a world view. Furthermore, advertisements being the embodiment of new trends and styles in accordance with changing space and time are the best ways of ideological investments. To conclude, it can be said that humor as a monotony breaker (Atta, 2011) is a selling strategy in an advertisement that is of high significance because, "people do not buy from clowns" but their humor force them to buy the product, therefore.

\section{References}

Aazam, F., Baig, F. Z., Baig, T., Khaliq, S., Azam, A., Shamshad, S., \& Aslam, M. Z. (2019). A Critical Discourse Analysis of 'Fire and Fury: Inside the Trump White House' by Michael Wolff. International Journal of English Linguistics, 9(4), 192-199. https://doi.org/10.5539/ijel.v9n4p192

Abdelaal, N. M., \& Sase, A. S. (2014). Advertisement Analysis: A Comparative Critical Study. Advances in Language and Literary Studies, 5(6), 254-259. https://doi.org/10.7575/aiac.alls.v.5n.6p.254

Abid, S., \& Bilal, Z. (2018). Political Communication and TV Comedy: Examining the Descriptive Patterns of Political Entertainment on Mainstream TV Channels of Pakistan. Journal of Media Studies, 33(1), 45-68.

Atta, A. (2011). Humor - Need to Break Monotony in Ufone TVCs (A review). Retrieved January 25, 2019, from https://propakistani.pk/2010/10/04/humor-need-to-break-monotony-in-ufone-tvcs/

Baig, F. Z., Yousaf, W., Aazam, F., Shamshad, S., Fida, I., \& Aslam, M. Z. (2019). Power, Ideology, and Identity in Digital Literacy: A Sociolinguistic Study. International Journal of English Linguistics, 9(4), 252-264. https://doi.org/10.5539/ijel.v9n4p252

Bardici, M. (2012). A Discourse Analysis of the Media Representation of Social Media for Social Change-The Case of Egyptian Revolution and Political Change. Master Thesis, Malmö University, Sweden. Retrieved October 12, 2019, from https://muep.mau.se/bitstream/handle/2043/14121/BardiciVMDP12.pdf

Chang, W. Y., \& Chang, I. Y. (2014). The Influences of Humorous Advertising on Brand Popularity and Advertising Effects in the Tourism Industry. Sustainability, 6, 9205-9217. https://doi.org/10.3390/su6129205

Chiapello, E., \& Fairclough, N. (2002). Understanding the new management ideology: A transdisciplinary contribution from critical discourse analysis and new sociology of capitalism. Discourse \& Society, 13(2), 185-208. https://doi.org/10.1177/0957926502013002406

Elbers, J. (2013). Humorous Advertisements and their effectiveness among customers with different motivational values. Master Thesis, University of Twente. Retrieved October 14, 2019, from 
https://essay.utwente.nl/63592/1/Elbers_Judith_-s_0182427_scriptie.pdf

Fairclough, N. (1989). Language and Power. London: Longman.

Fairclough, N. (1992). Discourse and Social Change. Cambridge: Polity Press.

Fairclough, N. (1995a). Media Discourse. London: Arnold.

Fairclough, N. (1995b). Critical Discourse Analysis: The Critical Study of Language. London: Longman.

Fairclough, N. (2003). Analyzing Discourse: Textual Analysis for Social Research. London: Routledge. https://doi.org/10.4324/9780203697078

Godil, A., Mallick, M., Adam, A., ... Shahid, N. (2017). Prevalence and severity of depression in a Pakistani population with at least one major chronic disease. Journal of Clinical and Diagnostic Research, 11(8), OC05-OC10. https://doi.org/10.7860/JCDR/2017/27519.10329

Haider, T., \& Shakib, S. (2017). A Study On The Influences of Advertisement On Consumer Buying Behavior. Business Studies Journal, 9(1).

Jazz (Pakistan Mobile Communications Limited). (2010, October 10). Jazz Na Qabil-e-Yaqeen Offer [Advertisement]. Retrieved from https://www.youtube.com/watch?v=OL4Wvsbq2-M

Jhally, S. (1987). Codes of Advertising. New York: St. Martin's Press.

Kang, M. E. (1997). The portrayal of women's images in magazine advertisements: Goffman's gender analysis revisited. Sex Roles, 37(11-12), 979-996. https://doi.org/10.1007/BF02936350

Kaur, K., Arumugam, N., \& Yunus, N. M. (2013). Beauty Product Advertisements: A Critical Discourse Analysis. Canadian Center of Science and Education, 9(3), 61-71. https://doi.org/10.5539/ass.v9n3p61

Koneska, L., Teofilovska, J., \& Dimitrieska, S. (2017). Humor in Advertising. European Journal of Economics and Business Studies, 3(2), 116-123. https://doi.org/10.26417/ejes.v8i1.p116-123

Kotler, A. (2004). Principles of Marketing. New Jersey: Pearson Education.

Kress, G., \& van Leeuwen, T. (1996). Reading images. The grammar of visual design. London: Routledge.

Louie, D., Brook, K., \& Frates, E. (2016). The Laughter Prescription: A Tool for Lifestyle Medicine. American Journal of Lifestyle Medicine, 10(4), 262-267. https://doi.org/10.1177/1559827614550279

Mehmood, H., \& Masood, S. (2016), Impact of Humor in Advertising on Consumer Purchase Intention: A Study on Ufone Network from Telecommunication Sector in Pakistan. International Review of Management and Business Research, 5(3), 1232-1240.

Morris, P. K., \& Nichols, K. (2013). Conceptualizing Beauty: A Content Analysis of U.S. and French Women's Fashion Magazine Advertisements. Online Journal of Communication and Media Technologies, 3(1), 4974.

Muda, M., Musa, R., \& Putit, L. (2017). Celebrity Endorsement in Advertising: A double-edged sword. Journal of ASIAN Behavioural Studies, 2(3), 21-32. https://doi.org/10.21834/jabs.v2i3.188

Najafian, M., \& Dabaghi, A. (1991). Hidden Language of Advertising: A Semiotic Approach (pp. 20-26). Proceedings of the International Conference: Doing Research in Applied Linguistics. Retrieved September 26, 2019, from https://pdfs.semanticscholar.org/f977/eefe6e79d79709388868296d21db39a7c81e.pdf

Nwankwo, B. E., Aboh, J. U., Obi, T. C., Agu, S. A., \& Sydney-Agbor, N. (2013). Influence of Advertising Appeals and Personality on Telecoms Consumption Preferences in Nigeria. International Journal of Academic Research in Business and Social Sciences, 3(9), 229-237. https://doi.org/10.6007/IJARBSS/v3-i9/205

Orth, U. R., \& Holancova, D. (2004). Men's and women's responses to sex role portrayals in advertisements. International Journal of Research in Marketing, 21(1), 77-88. https://doi.org/10.1016/j.jiresmar.2003.05.003

Oxford Dictionary. (2019). Humor Definition. Retrieved September 26, 2019, from https://www.lexico.com/en/definition/humour

Robinson, A. (2011, October 14). An A to Z of Theory | Roland Barthes: Death of the Author. Retrieved September 26, 2019, from https://ceasefiremagazine.co.uk/in-theory-barthes-4/

Scozzafava, G., Gerini, F., Boncinelli, F., Contini, C., Marone, E., \& Casini, L. (2019). Organic milk preference: 
is it a matter of information? Appetite, 144(2020), 104477. https://doi.org/10.1016/j.appet.2019.104477

Sekulovska, N. (2007). Humor, its justification and efficiency in the promotion of the products and services on the Macedonian market, Annual Review of the Faculty of Economics, Skopje, Republic of Macedonia.

Shimp, T. A., (2010). Integrated marketing communication in advertising and promotion (8th international ed.). Hampshire: Thomson South-Western.

Sinclair, J. (1987). Images Incorporated: Advertising as Industry and Ideology. New York: Croom Helm.

Transliteration. (2019). From Urdu to Roman Urdu. Retrieved September 26, 2019, from https://www.ijunoon.com/transliteration/?type=269201975854

Tuzla, H. (2012). Does sex in print-ads affect perceived product specifications in conservative societies? The case of Turkey. Social and Behavioral Sciences, 62, 1133-1137. https://doi.org/10.1016/j.sbspro.2012.09.194

Ufone (Pak Telecom Mobile Limited). (2010, July 26). Ufone Saaf Awaz TVC [Advertisement]. Retrieved from $\mathrm{https} / / /$ www.youtube.com/watch?v=VeFgKwdvjUE

van Dijk, T. A. (1995). Discourse as Structure and Process. London: Sage.

van Dijk, T. A. (1998). Ideology: A multidisciplinary approach. London: Sage.

Weinberger, M. G., \& Gulas, C. S. (1992). The impact of humor in advertising: A review. Journal of Advertising, 21(4), 35-59. https://doi.org/10.1080/00913367.1992.10673384

World Economic Forum, USA. (2016). Digital Media and Society: Implications in a Hyperconnected Era. Retrieved October 12, 2019, from http://www3.weforum.org/docs/WEFUSA_DigitalMediaAndSociety_Report2016.pdf

\section{Copyrights}

Copyright for this article is retained by the author, with first publication rights granted to the journal.

This is an open-access article distributed under the terms and conditions of the Creative Commons Attribution license (http://creativecommons.org/licenses/by/4.0/). 